\title{
CARACTERÍSTICAS DO COMPORTAMENTO EMPREENDEDOR DURANTE O INSUCESSO
}

\author{
BEHAVIORAL CHARACTERISTICS OF ENTREPRENEURS DURING BUSINESS \\ UNSUCCESSFULNESS
}

Recebido em 14.12.2013. Aprovado em 22.09.2014 Avaliado pelo sistema double blind review

DOI: http://dx.doi.org/10.12712/rpca.v8i3.337

\author{
Isabel Bohrer Scherer \\ isa.ufsm@yahoo.com.br \\ Universidade Federal de Santa Maria - Santa Maria- RS - Brasil \\ Italo Fernando Minello \\ italo.minello@uol.com.br \\ Universidade Federal de Santa Maria - Santa Maria- RS - Brasil
}

Resumo: Este artigo tem como objetivo analisar o comportamento resiliente e os estilos de enfrentamento de empreendedores durante o insucesso empresarial. A pesquisa caracteriza-se como qualitativa, exploratória, baseada em pesquisa empírica. Adotou-se a entrevista semiestruturada como instrumento de coleta de dados, que foi realizada com 13 empreendedores paulistas que vivenciaram o insucesso empresarial. A análise dos dados foi a partir da aplicação da Escala de Funcionamento Defensivo e da técnica de análise de conteúdo. Como resultados constatou-se que os estilos de enfrentamento mais utilizados foram identificação projetiva, atuação e afiliação, o que significa que o empreendedor durante o insucesso empresarial projeta a outro a responsabilidade pelo seu fracasso, age sem o devido planejamento ou reflexão, porém, busca ajuda para minimizar tal situação; além disso, encontrou-se o estigma do fracasso, a aliança ou apoio externo, a perturbação emocional e os aspectos econômicos, como as principais repercussões do fracasso empresarial.

Palavras-chave: Insucesso Empresarial. Comportamento Resiliente e Estilos de enfrentamento.

\begin{abstract}
The purpose of this article was to analyze the resilient behavior and confronting styles of entrepreneurs during business unsuccessfulness. The research was characterized as qualitative, exploratory; based on empirical research. The semi-structured interview was used as an instrument of data collecting which was applied to 13 entrepreneurs from Sao Paulo who experienced business unsuccessfulness. The analysis of data was done from the application of the Defensive Functioning Scale and the content analysis technique on the reports of the interviewees. As a result, the confronting styles most utilized were projective identification, acting and affiliation, which meant that during the process of business unsuccessfulness, the entrepreneurs projected the responsibility of their failure to someone else and acted without the proper planning or reflection. However, the entrepreneurs searched for help to minimize such situations. Other than that, the stigma of failure, the alliance or the external support, the emotional disturbance and the economical aspects were found as the main repercussions of business unsuccessfulness.
\end{abstract}


Keywords: Business Unsuccessfulness. Resilient Behavior. Confronting Styles

\section{Introdução}

A ação empreendedora tem seus desafios e aprendizados, a qual segundo dados apresentados no relatório GEM - Global Entrepreneurship Monitor - de 2012, mostram indicadores favoráveis em relação às oportunidades no ambiente e à capacidade individual para a abertura de novos negócios.

No entanto Casado (2002) evidencia que sob o ponto de vista empresarial, as organizações estão expostas às mudanças e estas podem influenciar seu comportamento no mercado, como também as ações e percepções das pessoas que as compõem.

Quando o contexto envolve uma situação estressora, como no caso do insucesso empresarial, essa capacidade de avaliação é afetada de maneira distinta, provocando diferentes reações nos indivíduos (LAZARUS e FOLKMAN,1984).Shepherd (2003) complementa a ideia afirmando que o fracasso empresarial muitas vezes é visto pelo indivíduo como uma perda pessoal, gerando uma resposta emocional negativa.

Essa resposta pode ser interpretada por uma incapacidade de administrar a adversidade, pois, segundo Collins (2010), pode ser um processo que foge do controle do empreendedor, muitas vezes esgotando a capacidade do indivíduo em lidar com a adversidade, esgotando seus recursos mentais e minimizando as esperanças de recuperação.Esse esgotamento, na visão de Yunes e Szymanski (2001) é evidenciado como uma necessidade de o indivíduo buscar um equilíbrio interno para obter condições de enfrentar a adversidade. Essa capacidade de enfrentamento representa o processo da resiliência (GROTBERG, 2005; INFANTE, 2005; LUTHAR e ZIGLER, 1991; RUTTER, 1985), o qual sugere a capacidade de superação de crises e de adversidades por parte das pessoas, grupos e ou organizações que as vivenciam.

De acordo com Grotberg (2005), a resiliência pode ser considerada como um processo, que envolve fatores, comportamentos e resultados. Uma das variáveis que também pode ser considerada dentro do escopo da resiliência, na visão de Minello (2010), são os estilos de enfrentamento ou mecanismos de defesa do indivíduo, os quais são usados como formas de defesa ou proteção do indivíduo diante de grandes estressores, como no caso do insucesso empresarial.

Nesse sentido, buscando contribuir para a ampliação do conhecimento sobre esta temática, o presente artigo tem como objetivo analisar o comportamento resiliente e os estilos de enfrentamento de empreendedores que vivenciaram o insucesso, especificamente durante o insucesso empresarial.

\section{Atividade Empreendedora No Brasil}

No relatório Endeavor Brasil (2013) constam os resultados da pesquisa sobre a atividade empreendedora no Brasil, que evidenciam a percepção do brasileiro sobre empreendedorismo e empreendedores como positiva e otimista. Cerca de $90 \%$ dos brasileiros acreditam, por exemplo, que "empreendedores são geradores de emprego", no entanto, a possibilidade de falência ocupa segundo lugar no que se refere à opinião dos brasileiros sobre principais riscos 
da decisão de abrir negócio próprio.

Segundo o relatório GEM (2012), a Taxa Total de Empreendedores envolvidos com algum tipo de empreendimento, seja ele, nascente, novo ou estabelecido correspondeu a $30,2 \%$, o que significa que cerca de 36 milhões de brasileiros estavam empreendendo no período pesquisado, representando a $10^{\mathrm{a}}$ colocação no ranking mundial. Como condições que afetam o empreendedorismo, a mesma pesquisa atribui como fatores favoráveis, o clima econômico $62,1 \%$, normas culturais e sociais 41,4\%; e, infraestrutura comercial e profissional 26,4\%; por outro lado, como fatores limitantes, a pesquisa apontou políticas governamentais 77\%, apoio financeiro 59,8\%, e, educação e capacitação 39,1\%. Esta constatação evidencia a relevância econômica e social da atividade empreendedora no Brasil, o que requer ações governamentais e não governamentais para a consolidação de tal atividade no país.

\section{Empreendedor e Comportamento do Empreendedor}

Mintzberg (2011) aponta que vários estudos demonstram que gestores - considerados neste artigo como empreendedores que gerem seus próprios negócios - trabalham em um ritmo implacável; suas atividades parecem caracterizar-se por brevidade, variedade, fragmentação e descontinuidade; e, são fortemente orientados para a ação. McClelland (1961) identificou as características mais comuns nos empreendedores de sucesso, como características do comportamento empreendedor.

Dentre elas, as que mais se destacaram foram: busca de oportunidades e iniciativa; persistência; comprometimento; exigência de qualidade e eficiência; correr riscos calculados; estabelecimento de metas; busca de informações; planejamento e monitoramento sistemático; persuasão e rede de contatos; independência e autoconfiança.

A teoria de McClelland (1961) foi fundamentada na motivação psicológica e é composta por três necessidades básicas: realização; afiliação e poder. Já para Hisrich e Peters (2009), o comportamento do empreendedor pode ser analisado sob três aspectos: lócus de controle interno, traduzido pelo sentimento e crença de que seu sucesso e seu destino dependem de seu esforço e de seu trabalho; sentimentos de independência e necessidade de realização; e, propensão em assumir riscos em suas atividades empreendedoras.

Estes comportamentos remetem aos valores do empreendedor, no que ele acredita. No entanto, Finkelstein (2007), considera certos comportamentos que podem levar o negócio do empreendedor ao colapso. 0 autor aponta características do comportamento de executivos nesse artigo entendidos como empreendedores -, apresentadas como sete hábitos de pessoas malsucedidas: veem a si mesmos e às suas empresas como dominadores do ambiente; identificam-se tanto com a empresa que não há limites claros entre seus interesses pessoais e os da organização; acham que tem todas as respostas; eliminam impiedosamente todos que não os seguem fielmente; são porta-vozes perfeitos da empresa, obcecados com sua imagem; subestimam grandes obstáculos; e, apegam-se obstinadamente ao que deu certo no passado.

Dotlich e Cairo (2004) consideram outras características que podem ser associadas àquelas apresentadas por Finkelstein (2007) e que contribuem para estimular o fracasso empresarial. Essas particularidades caracterizam o comportamento dos empreendedores e os tornam vulneráveis, são elas: arrogância, melodrama, temperamental, cauteloso, cético, reservado, ardiloso, excêntrico, passivo resistente, perfeccionista e obsequioso. 
Relacionando-se características comportamentais que estimulam o sucesso com aquelas que levam ao insucesso, constata-se que as características dos empreendedores de sucesso, sugeridas por McClelland (1961) - correr riscos calculados e autoconfiança - ,quando exacerbadas, na visão de Finkelstein (2007), poderão desencadear comportamentos, como subestimar grandes obstáculos e ter a certeza de que tem todas as respostas.

\section{Insucesso Empresarial}

A competitividade acirrada no mundo dos negócios faz com que as organizações se empenhem e foquem seus esforços na busca de respostas mais eficazes, rápidas e condizentes às necessidades do mercado. A manutenção do sucesso ao longo do tempo estimula o surgimento de certa apatia, ou comodismo, em função da posição confortável que o sucesso pode proporcionar. Tal situação evidencia um risco, inerente ao sucesso, que, por meio da miopia de seus gestores, coloca em risco a organização e faz emergir a possibilidade do insucesso empresarial.

Nesse sentido, Fleck (2009) afirma que o sucesso traz consigo o insucesso ou o risco do fracasso. A autora evidencia que os estudos empresariais estão centrados no sucesso organizacional, porém segundo Ortigara et. al. (2011) existe uma preocupação nos meios, político, acadêmico e empresarial com relação ao sucesso ou fracasso empresarial, pois existe alto índice de mortalidade.

No entanto, Robinson (2007) evidencia a complexidade na definição do que é fracasso empresarial, pois existem diversos fatores que influenciam tal situação e culminam no fracasso do negócio; dentre eles o autor enfatiza a aposentadoria, venda do negócio, falência, mau gerenciamento, atitudes e comportamentos inadequados dos empreendedores frente aos seus empreendimentos.

Bruno, Mcquarrie e Torgrimson (1992) definem o fracasso como uma descontinuidade do negócio, que pode ter várias causas, incluindo problemas legais, disputas na sociedade, morte ou simplesmente uma mudança de interesses. Este conceito é adotado por este artigo em função de que o mesmo é abrangente o suficiente para envolver diferentes enfoques, definições, conceitos e/ou fatores relacionados ao insucesso empresarial.

Collins (2010) acredita que existem fatores que contribuem para que as empresas declinem, como por exemplo, catástrofes e fraudes. No entanto, ressalta o aspecto comportamental do empreendedor, sugerindo a relação deste com os cinco estágios do declínio empresarial: excesso de confiança proveniente do sucesso; busca indisciplinada por mais; negação de riscos e perigos; luta desesperada pela salvação; e, entrega à irrelevância ou à morte. Para o autor, estes estágios não se tratam de um modelo de declínio corporativo, mas cinco estágios que evoluem em sequência.

Outra perspectiva sobre o insucesso empresarial, na visão de Shepherd (2003), é que o mesmo pode causar uma resposta negativa do empreendedor, inibindo a tomada de decisões, o processo cognitivo e estabelecendo uma condição míope em relação ao número de opções diante dessa adversidade. Nesse sentido, Mitroff (2001), ressalta a importância das reações emocionais de empreendedores em momentos de adversidade, pois as emoções negativas necessitam ser exploradas pelo indivíduo, para que o processo de aprendizagem diante deles se concretize (SHEPHERD, 2003). 
Tais reações constituem a base de análise do comportamento resiliente e dos estilos de enfrentamento de empreendedores que vivenciaram situações de adversidade, como no caso do insucesso empresarial. No relatório Endeavor Brasil (2013), Juliano Seabra, diretor-geral da instituição no país, discorre sobre a necessidade de desenvolver histórias, disseminar a aprendizagem e os ensinamentos que o fracasso proporciona, para que as pessoas tenham uma ideia mais próxima da realidade, principalmente aqueles que tem interesse em se aventurar no mundo dos negócios.

\section{Resiliência e Características Resilientes}

Segundo Yunes (2003) a maioria dos estudos sobre resiliência tem como foco o estudo em crianças ou adolescentes, focalizando "traços e disposições pessoais" (p.78). No entanto, Masten (2001) reconhece a resiliência como um fenômeno comum e presente no desenvolvimento de qualquer ser humano. Grotberg (2005, p.15) ratifica o pensamento de Masten (2001) definindo resiliência como: "A capacidade humana para enfrentar, vencer e ser fortalecido ou transformado por experiências de adversidade".

Nesse sentido, Flores (2010) corrobora a ideia de Grotberg (2005) ao considerar resiliência como obtenção de êxito apesar da adversidade, no entanto, Fontes (2010) evidencia que resiliência não deve ser considerada um traço individual, pois pode variar em função da interação com o meio e desafios específicos. Complementando, Infante (2005) evidencia que a resiliência tenta gerar processos que abarquem o indivíduo e seu ambiente social, auxiliando-o a superar a adversidade, adaptar-se à sociedade e obter melhor qualidade de vida.

Essa perspectiva pode ser constatada nos pilares da resiliência sugeridos por Ojeda (1997, 2005) - introspecção; independência; capacidade de se relacionar; iniciativa; humor; criatividade; moralidade e autoestima consistente -, que enfatizam condições e habilidades necessárias para que o indivíduo amplie sua capacidade de adaptação e de superação diante de situações de adversidades. Diante disso, percebe-se que a resiliência está relacionada ao surgimento do estresse, ou à percepção deste como tal por parte do indivíduo, frente a situações de adversidade vivenciadas por ele.

Nesse sentido, para este artigo, o conceito de resiliência adotado é aquele sugerido por Grotberg (2005) que a define como um processo que, conforme apresentado anteriormente, evidencia a capacidade humana para enfrentar, vencer e sair fortalecido ou transformado pela experiência de uma situação adversa. A adversidade, para fins deste artigo, é relacionada ao insucesso empresarial, sendo o mesmo considerado como o estressor para o indivíduo empreendedor.

Diante disso, o estresse pode ser considerado como necessário para o surgimento de um comportamento adaptativo e estimulante às reações no sentido de superá-lo ou minimizá-lo. Essa perspectiva caracteriza o estresse como necessário para que o processo da resiliência se inicie contribuindo para o surgimento do comportamento resiliente, na visão de Yunes e Szymanski (2001). Esse comportamento, para Grotberg (2005), é um dos elementos capazes de promover o processo da resiliência, contribuindo para que o indivíduo assimile o impacto provocado pela adversidade. Diante disso, Rutter (1985) sugere quatro mecanismos protetores que podem minimizar os efeitos da adversidade e os riscos psicológicos decorrentes de tal situação; são eles: redução do impacto aos riscos; redução de reação negativa em cadeia; promoção, estabelecimento e manutenção da autoestima e da auto eficácia.

Esses fatores de proteção, na visão de Minello (2010), sustentam os estilos de enfrentamento 
utilizados pelo indivíduo diante de situações estressoras, representando características comportamentais deste em relação ao meio em que está inserido.No intuito de mensurar a adoção destes estilos e sua respectiva influência sobre o comportamento do indivíduo, diante de um grande estressor, como no caso do insucesso empresarial. Para isso, adotou-se a Escala de Funcionamento Defensivo (EFD), a qual foi desenvolvida pela American Psychiatric Association (APA, 2002) e disponibilizada no manual DSM-IV-TR. Essa escala é estruturada em sete níveis de defesa, em ordem decrescente quanto à capacidade que a pessoa tem de se proteger ou de encarar uma circunstância adversa.

\section{Método}

Este estudo caracteriza-se como qualitativo do tipo exploratório, baseado em pesquisa empírica. Para Richardson et al. (2011), a abordagem qualitativa justifica-se, sobretudo, por ser uma forma adequada para entender a natureza de um fenômeno social; sendo sua aplicação adequada a situações em que se busca compreender aspectos psicológicos relacionados ao fenômeno em estudo.

Com relação ao caráter exploratório, segundo Sampieri et al. (2006, p. 99), estes estudos são utilizados "quando o objetivo é examinar um tema ou problema de pesquisa pouco estudado, do qual se tem muitas dúvidas ou não foi abordado antes." As unidades de análise foram definidas por conveniência, visto que a escolha desses indivíduos requer cuidado para que atendam ao perfil e ao objetivo da pesquisa - analisar o comportamento resiliente e os estilos de enfrentamento de empreendedores que vivenciaram o insucesso, especificamente durante o insucesso empresarial -; e, à dificuldade de encontrar empreendedores predispostos a falar sobre suas experiências adversas.

No intuito de conseguir pesquisados, foram contatados 60 escritórios de advocacia que trabalham com falência empresarial na cidade de São Paulo/BR. Nesse sentido, a coleta de dados foi realizada com treze empreendedores que vivenciaram o insucesso empresarial na Grande São Paulo, os quais representam as unidades de análise desta pesquisa. 0 instrumento de coleta de dados foi um roteiro de entrevistas previamente elaborado, composto por uma seção de dados complementares de suporte (gênero, idade, formação e há quanto tempo montou seu empreendimento) e outras vinte e cinco perguntas, seccionadas em quatro blocos: quanto á história de vida, quanto à trajetória profissional, quanto ao processo de descontinuidade e quanto ao processo da resiliência (MINELLO, 2010).

Os dados coletados foram gravados, transcritos e posteriormente analisados em dois momentos distintos: o primeiro, com base na aplicação da EFD (APA, 2002); e o segundo, por meio da definição das categorias de análise não a priori, a partir dos relatos dos entrevistados, são elas: estigma do fracasso; aliança e apoio externo; perturbação emocional; e, aspectos econômicos. A análise dessas categorias foi realizada a partir da aplicação da técnica de análise de conteúdo (BARDIN, 2011).

A utilização da Escala de Funcionamento Defensivo (EFD) se justifica nesta pesquisa, pois pode ser usada como uma fonte de registros para a análise dos dados e proporciona, além dos registros sistemáticos, validade e confiabilidade para este trabalho. A EFD faz parte do manual DSM-IV-TR (APA, 2002) que disponibiliza, dentre outros instrumentos e diretrizes, escalas desenvolvidas com a finalidade de avaliar o grau de funcionamento do indivíduo e seus estilos de enfrentamento diante da adversidade. 


\section{Análise dos Resultados}

\section{Resultados da Aplicação da EFD}

0 quadro 1 apresenta os resultados com base nos resultados das aplicações individuais da EFD referente ao período de pesquisa.

\begin{tabular}{|l|l|l|l|l|l|l|l|l|l|l|l|l|l|l|}
\hline \multirow{2}{*}{$\begin{array}{l}\text { Estilos de } \\
\text { enfrentamento }\end{array}$} & \multicolumn{1}{|c|}{ E } & E & E & E & E & E & E & E & E & E1 & E1 & E1 & E1 & FREQ. \\
& 1 & 2 & 3 & 4 & 5 & 6 & 7 & 8 & 9 & 0 & 1 & 2 & 3 & \\
\hline Afiliação & $\mathrm{X}$ & & & & & & $\mathrm{X}$ & $\mathrm{X}$ & $\mathrm{X}$ & & $\mathrm{X}$ & & $\mathrm{X}$ & 6 \\
\hline Antecipação & & & & $\mathrm{X}$ & & & & $\mathrm{X}$ & & & & & $\mathrm{X}$ & 3 \\
\hline Autoafirmação & & & & & & $\mathrm{X}$ & $\mathrm{X}$ & & & & & & & 2 \\
\hline Auto-observação & & & & $\mathrm{X}$ & & & & $\mathrm{X}$ & $\mathrm{X}$ & & & & & 3 \\
\hline Anulação & & & $\mathrm{X}$ & $\mathrm{X}$ & & & & & & & & & & 2 \\
\hline Deslocamento & & & & & & & & $\mathrm{X}$ & & & & & & 1 \\
\hline Formação reativa & & & & & & & $\mathrm{X}$ & & & $\mathrm{X}$ & & & $\mathrm{X}$ & 3 \\
\hline Isolamento do afeto & & & & & & & & & & $\mathrm{X}$ & & & & 1 \\
\hline Desvalorização & & & & & & $\mathrm{X}$ & & & & & $\mathrm{X}$ & $\mathrm{X}$ & & 3 \\
\hline Onipotência & & & & & & & & & & $\mathrm{X}$ & & & & 1 \\
\hline Negação & & & $\mathrm{X}$ & & & & & & & & & $\mathrm{X}$ & $\mathrm{X}$ & 3 \\
\hline Racionalização & & $\mathrm{X}$ & & & & & & & & & $\mathrm{X}$ & & 2 \\
\hline Cisão da autoimagem & & & & & & & & & & & $\mathrm{X}$ & & & 1 \\
\hline $\begin{array}{l}\text { Identificação } \\
\text { projetiva }\end{array}$ & & $\mathrm{X}$ & $\mathrm{X}$ & $\mathrm{X}$ & $\mathrm{X}$ & $\mathrm{X}$ & & $\mathrm{X}$ & $\mathrm{X}$ & & & $\mathrm{X}$ & & 8 \\
\hline Atuação & $\mathrm{X}$ & $\mathrm{X}$ & & & $\mathrm{X}$ & & & & $\mathrm{X}$ & $\mathrm{X}$ & $\mathrm{X}$ & $\mathrm{X}$ & & 7 \\
\hline $\begin{array}{l}\text { Queixa com rejeição } \\
\text { de ajuda }\end{array}$ & & & & & $\mathrm{X}$ & & & & & & $\mathrm{X}$ & $\mathrm{X}$ & & 3 \\
\hline Retraimento apático & & & & & & $\mathrm{X}$ & & & & & $\mathrm{X}$ & & & 2 \\
\hline Distorção psicótica & $\mathrm{X}$ & $\mathrm{X}$ & & & & $\mathrm{X}$ & & & $\mathrm{X}$ & & $\mathrm{X}$ & & & 5 \\
\hline
\end{tabular}

Quadro 1 - Escala do Funcionamento Defensivo, foco nos estilos de enfrentamento dos empreendedores - Durante a Descontinuidade do Negócio.

Fonte: Minello (2010).

Analisando-se os resultados da aplicação da EFD, apresentados no quadro 1, constata-se que a identificação projetiva é o estilo de enfrentamento mais utilizado pelos entrevistados durante a descontinuidade do negócio. Evidencia-se que nesse momento os empreendedores entrevistados, em sua maioria, atribuem a outros a responsabilidade pela situação adversa; e, a atuação, o segundo estilo de enfrentamento mais usado. Isso descreve que, nesse momento de pressão, a racionalidade dá espaço para ação com o objetivo de superar a adversidade de qualquer maneira. A afiliação como estilo de enfrentamento, demonstra que nesse momento o empreendedor entrevistado, aparentemente, está predisposto a buscar ajuda e a ouvir outras pessoas.

Em contrapartida, a distorção psicótica, constatada por meio da presença de pensamentos delirantes, como a ideação suicida, a mendigagem e o alcoolismo, representam comportamentos que vão de encontro à superação da adversidade do fracasso empresarial. Esse aspecto parece merecer atenção, visto que a ordem de proeminência deste estilo de enfrentamento é alta, dentre aqueles que o apresentaram. A onipotência, por sua vez, identificada em apenas um dos 
entrevistados durante o período do insucesso empresarial, parece evidenciar que nesse momento o empreendedor entrevistado passa por um processo de alta pressão repleta de sentimentos e emoções, o que sugere um comportamento de retraimento por parte do entrevistado em função da situação vivenciada.

\section{Análise das categorias definidas não a priori}

Estigma do Fracasso- Esta foi uma das categorias mais frequentemente percebida nas narrativas dos entrevistados. Todos enfatizaram a sensação desagradável de perceber que os outros o enxergavam como fracassado, como se estivessem "marcados" pelo insucesso empresarial. Além disso, a quebra do crédito provocava nos empreendedores pesquisados uma sensação de impotência em relação à situação e à nebulosidade da descontinuidade do negócio. De acordo com Goffman (1963), o surgimento do estigma se dá no momento em que o indivíduo apropriando-se da crença de que os outros o consideram um fracassado, no caso do insucesso empresarial, assume esse "rótulo", criado por ele mesmo, o qual influencia seu comportamento e sua percepção do que acontece ao seu redor. Diante disso, apresentam-se trechos dos relatos de E1, E10 e E12, que ilustram a influência do estigma na vida e no comportamento dos empreendedores entrevistados.

"Eu lembro muito bem que eu dirigia a congregação e os irmãos perceberam que na minha casa não tinha nada, tinha, talvez, o arroz e o feijão que tava na panela, e se reuniram e me deram uma cesta básica, mas o meu orgulho não permitiu eu receber aquela cesta básica.... não vô pegar', eles começaram a ficar em conflito, abismados, porque como o dirigente tá precisando de ajuda e não quer ajuda". (E1)

"Mais assim, a parte mais difícil mesmo é que você tem que mudar um pouco o seu estilo de vida, né. Pega muito na sua parte pessoal também, né, acho que essa é a pior parte, é, coisas que você fazia, você não pode mais fazer, aí vem restrição de crédito, você vai comprar uma bolacha no cartão de crédito, você não pode comprar. Acho que essa parte pega muito, e quando tá envolvido com família então, problemas de esposa e filhos, é pior." (E10).

"Meu filho foi na casa de um, de um, de um amigo uma vez e a mãe, né, fui buscá-lo de Fiat Uno, né, 'como é que seu pai dá curso rumo ao sucesso com um Fiat Uno, né?! Marido dela trabalhava numa multinacional, tinha carro da empresa e tal, aquela história toda, né. E aí meu filho veio me contar isso e eu fiquei magoado pra caramba, né?!" (E12)

Aliança ou Apoio Externo- Os aspectos sociais, tipicamente, envolvem perda de status e identidade social, bem como alienação e restrição a contatos sociais (PAYNE e HARTLEY, 1987). No entanto, quando o <0\}indivíduo está com alguma dificuldade ou perturbação emocional pode buscar apoio e suporte emocional. A família e as redes sociais também possuem papel importante na construção de uma resiliência mais efetiva. Relações interpessoais estáveis proporcionam uma importante fonte de apoio emocional, assim como o apoio social da comunidade em geral também pode servir como um alicerce para a resiliência (GREFF e JOUBERT, 2007). Apresenta-se a seguir, alguns trechos dos relatos dos entrevistados que denotam a relevância do apoio externo durante o insucesso empresarial:

"E aí naturalmente assim, aí um amigo passava aqui, me levava pra ir pra praia, outro passava aqui me levava pra ir jantar, outro passava aqui 'vamo pro...' Eu tava paparicado, então assim nem sentia muito, né, ou ligava 'vô passar aí, vamo pro cinema', eu cheguei naquele momento que eu não tinha dinheiro pra nada, então um vinha 'vamo' no supermercado, vou fazer uma compra pra você”. (E2) 
“Carlos cabeça, que era o diretor lá da empresa, a família teve uma afinidade muito grande, as meninas tinha dois aninhos, ele tinha filha pequena, começamos a ter uma convivência muito legal, fomos pra praia, sítio, comecei a dar uma vida melhor pra minha família, começamos, né, a reerguê novamente, aí a empresa emprestou o dinheiro pra mim, foi uma coisa muito bacana..." (E9)

Segundo alguns autores (LUTHAR et al., 2000; WERNER e SMITH, 1992), a família e as redes de apoio social representam fatores externos que podem contribuir para a promoção da capacidade de enfrentamento do indivíduo em situações adversas; o que pode ser constatado no trecho do relato de E1.

"Então recomecei. Recomecei. Tive um amigo, eu tenho que falar dele, que foi a pedra chave... bom, esse amigo, no período que eu estava preste a virar um marginal, ele sentô comigo e disse assim: Anderson, eu sei que você é capaz, mais se você, se você qué persisti nisso que você quer fazer, ser um marginal, eu tenho que me afastar de você porque você vai me trazer, vai me trazer afastamento de pessoas boas, pessoas boas vão se afastar de mim porque estou próximo de você". (E1)

Para Minuchin (1990), a família é uma unidade social que desenvolve múltiplos papéis fundamentais para o crescimento psicológico do sujeito, marcando as diferenças sociais e culturais, mas com raízes universais. A família é uma organização de apoio, proteção, limites e socialização. Tem uma proposta e propriedades de autoperpetuação; uma vez favorecido um processo de mudança, a família o preservará, pois as experiências são qualificadas dentro dela e permanecem na vida do grupo.

"Eu, eu vô pra rua, sem local pra trabalhar, e termino virando mendigo e não acreditava e fedia. Não tinha local pra tomar banho, não tinha amigos, o dinheiro que fazia na rua com artesanato bebia, quando dava pra fazer e ficava viajando, aqui, litoral [...] minha esposa e ela falou 'eu não acredito, porque a gente se conhece desde criança, eu te conheço desde criança, você é um empresário, você é um estudioso, você nunca teve mancha na sua vida, e agora você virar mendigo, é inacreditável'”. (E11)

Perturbação Emocional- De acordo com Lazarus e Folkman (1984), \{0>In particular, the psychoanalytical tradition within psychology views coping as realistic and flexible thoughts and acts that solve problems and thereby reduce stress (Lazarus \& Folkman 1984).<\}0\{>a psicologia vê o conceito de "lidar com alguma coisa" (tentativa de superação ou enfrentamento) como pensamentos e ações realistas e flexíveis que resolvem problemas, o que decorre na redução do estresse.

Essa definição focava na cognição e nas percepções e pensamentos dos indivíduos em relação às suas relações e interações com o ambiente. Os autores ampliaram essa visão psicanalítica, redefinindo o conceito de estratégias de enfrentamento como "esforços comportamentais e cognitivos em constante mudança para gerenciar demandas externas e/ou internas específicas que são avaliadas como esgotadoras ou excedentes aos recursos do indivíduo" (1984, p. 141).

Nesse sentido, a adversidade afeta de maneira significativa a vida daqueles que estão, direta ou indiretamente, envolvidos e, consequentemente, também repercute em seu estado emocional e em sua saúde mental, potencializando seu sofrimento (BARLACH, 2005; HISRICH e PETERS, 2009). No caso do insucesso empresarial, essa repercussão pode acarretar consequências e 
desvios comportamentais que afetam diretamente as relações do indivíduo empreendedor com os diferentes grupos sociais com os quais interage, bem como a imagem que tem de si mesmo, como, por exemplo: perda de identidade, no caso da mendigagem; do alcoolismo e da depressão, que podem ser causas ou consequências da perturbação emocional; e em sintomas de desequilíbrio emocional, como a ideação suicida.

"Então, por exemplo, eu nunca perdi o sono, eu nunca deixei de dormir, eu nunca tomei remédio pra dormir, eu tomei uns antidepressivos, assim, porque eu tive momentos de querer cometer suicídio, achava que a vida não valia a pena, aquelas coisas todas, quando você tá muito depressivo, né". (E1)

“Eu voltei pra casa aquele dia arrasado... tá tudo errado, pra mim tá tudo errado.' Eu me lembro bem que, naquele momento, eu coloquei uma cadeira próximo do guarda-roupa, e peguei uma arma que tava em cima do guarda-roupa do meu cunhado que, sendo policial, deixava ela fácil ali. Coloquei sobre a minha cabeça e pensei em atirar". (E2)

"[...] você deita à noite pra dormir, pessoas que passaram por isso devem saber... não dormem... Eu fiz três cirurgias no rim, pra você ter uma idéia, eu tomava uma garrafa de uísque por noite. Depois disso, eu entrei em depressão, comecei a trabalhar, porque na época eu não tinha dinheiro pra comprar nem leite, eu entrei num processo e fiquei depressivo". (E9)

Aspectos econômicos- 0 aspecto econômico envolve pressão financeira causada pela falta de receita (BRIEF et al. 1995), and in the case of business discontinuance may involve personal debts incurred to fund the failed business.1995) e, no caso da descontinuidade do negócio, pode envolver dívidas pessoais incorridas para financiar o negócio fracassado. De acordo com Ferreira (2008) existem outros fatores, além do contexto econômico que influenciam a capacidade ou a competência dos indivíduos para administrar o próprio dinheiro.

A autora sugere que a identificação desses fatores parece contribuir para ampliar a compreensão do comportamento econômico do indivíduo diante do insucesso empresarial, são eles: aceitação social, socialização econômica, comparação social, estilo de administração financeira, comportamento de consumo, horizonte temporal individual, atitude e Lócus de controles frente ao endividamento.

0 aspecto econômico que o empreendedor sofre envolve pressão financeira causada pela falta de receita (BRIEF et al., $<0\}\{0>1995$ ), e, no caso de cessação de atividades empresariais pode envolver dívidas pessoais contraídas para financiar o fracasso do negócio que descontinuou. A seguir, são apresentados alguns trechos $<\} 0\{>$ que evidenciam as colocações acima em relação ao aspecto econômico diante do fracasso, dentre os empreendedores entrevistados:

"Difícil aceitar. Então é a situação familiar, o que mais choca é a família naquela situação, você sem nenhuma moeda, e devendo muito no mercado, e meu último recurso que eu tinha, tinha $\mathrm{R} \$$ 7.500 no cartão de crédito, eu gastei o último crédito no cartão fazendo uma compra, fiquei devendo pro banco nacional naquela época... fiquei devendo pro banco $\mathrm{R} \$ 7.500,00$, tipo assim hoje, depois acabou tudo o recurso, pessoa falida privada, ação de despejo, sem comida..." (E9)

"Bom, eu acho que todas têm assim, o mesmo, assim, o caminho pra quebrar, o precipício, né. Basicamente começa a faltar dinheiro, falta verba, né, daí se você já esteve num período bom da empresa, você começa a vender bens, começa a desfazer assim, o empresário ele é quase que um jogador compulsivo, sabe, é um negócio meio complicado. [...] Primeiro ele vai quebrar na vida 
pessoal dele, estora primeiro a empresa, depois estora cartão de crédito, conta pessoal, conta física e tal, e chega o caso, que você vende casa e você não tem onde morar depois." (E10)

"Ah, as minhas preocupações eram, tipo familiar, né?! Que na época a minha esposa era sócia, e aí nós enfrentamos assim um período que ela tinha traumas, né, de o nome dela tá no Serasa, SPC, sei lá o quê... Aí primeiro cheque devolvido e tal, aquela porra toda, né?! E... e aquela história toda. Então isso é... Você ouvir que você criou problema porque você fez isso..." (E12)

\section{Conclusão}

Pode-se perceber que a resiliência é uma característica do ser humano ou uma capacidade humana universal (GROTBERG, 1997), o que não significa que todos os indivíduos apresentem a mesma capacidade de enfrentar situações adversas da mesma forma ou sequer possuam as mesmas condições de superá-las. A resiliência é uma condição interna do indivíduo, produzida por ele mesmo diante dessas situações, ou seja, ela surge de dentro pra fora (BARLACH, 2005). Isso fica evidente nos relatos dos entrevistados pela singularidade de suas posturas e pela diversidade de estilos de enfrentamento apresentadas diante do insucesso empresarial. Constata-se o surgimento de perturbação emocional durante a descontinuidade do negócio, momento em que o empreendedor entrevistado parece encontrar-se em uma situação de alta fragilização e de intensa nebulosidade, sente-se perdido e não sabe o que fazer. Esse momento caracteriza-se pela depressão (HAMILTON et al., 1993) em decorrência das repercussões do insucesso empresarial. A partir dos resultados da aplicação da EFD e dos relatos dos entrevistados, pode-se evidenciar que este momento é carregado de fortes emoções que podem provocar comportamentos destrutivos e psicóticos, como a ideação suicida (BION, 1966). Outros estilos considerados relevantes neste momento são a identificação projetiva, a atuação e a afiliação. 0 primeiro caracteriza a transferência inconsciente, portanto automatizada e não questionada, por parte do empreendedor entrevistado, de sentimentos e responsabilidades sobre a situação vivenciada, porém, erroneamente.

O segundo parece evidenciar que o empreendedor entrevistado busca desesperadamente alternativas para superar a situação de insucesso empresarial, o que o leva a aceitar sugestões descabidas, pois não tem condições de pensar racionalmente neste momento.

O terceiro, afiliação, descreve o aceite dessa busca por solução ou ajuda por meio da predisposição em compartilhar seus problemas e ouvir a opinião de outras pessoas. Evidenciase que os resultados encontrados no presente estudo devem ser interpretados exclusivamente em relação aos empreendedores entrevistados. Não é possível qualquer tipo de generalização, pois cada situação analisada está intimamente relacionada às características e à singularidade de cada indivíduo.

Por outro lado, constata-se que o aprofundamento da investigação em um grupo específico, representa também uma contribuição significativa para o conhecimento de tais indivíduos e para a reflexão sobre o insucesso empresarial, visto a escassez de estudos com características similares na literatura sobre o tema. Como sugestão para futuros estudos ressalta-se a necessidade de realização de novas pesquisas sobre o tema aqui explorado em função de sua relevância no contexto econômico e social, visto que são poucos os estudos que tem como foco o comportamento do empreendedor diante do insucesso empresarial.

\section{Referências}


APA. (2002), Manual diagnóstico e estatístico de transtornos mentais. (2 ed., 754-9). Porto Alegre: Artmed.

BARDIN, L. (2011), Análise de conteúdo. Lisboa: Edições 70.

BARLACH, L. (2005), «0 que é resiliência Humana? Uma contribuição para a construção do conceito». Dissertação de Mestrado - Instituto de Psicologia, Universidade de São Paulo.

BION, W.R. (1966), Os elementos da psicanálise. Rio de Janeiro: Zahar Editores.

BRIEF, A.; KONOVSKY, M.; GOODWIN, R.; LINK, K. (1995), «Inferring the meaning of work from the effects of unemploymentv». Journal of Applied Social Psychology 25: 693-711.

BRUNO A. V.; MCQUARRIE, E. F.; TORGRIMSON, C. G. (1992), «The evolution of new technology ventures over 20 years: patterns of failure, merger and survival». Journal of Business Venturing 7: 291-302.

CASADO, T. (2002), «0 comportamento das pessoas na organização. In: As pessoas na organização». Editora Gente, 6a edição, p. 235-246. São Paulo.

COLLINS, J. (2010), Como as gigantes caem: e por que algumas empresas jamais desistem. Rio de Janeiro: Elsevier.

DORNELAS, J. C. A. (2012), Empreendedorismo - transformando ideias em negócios. Rio de Janeiro: Editora Elsevier.

DOTLICH, D. L.; CAIRO, P. C.(2004), Por que os executivos falham? Rio de Janeiro: Elsevier. ENDEAVOR BRASIL, (2013). Empreendedores brasileiros: perfis e percepções. Disponível em http://promo.endeavor.org.br/pesquisa-empreendedores.relatório completo

FERREIRA, V. R. M. (2008), Psicologia econômica. Rio de Janeiro: Elsevier.

FINKELSTEIN, S. (2007), Por que executivos inteligentes falham. São Paulo: Makron Books. FLECK, D. (2009), «Archetypes of Organizational Success and Failure». Brasilian Administration Review (BAR), v. 6, n. 2, art. 1, p. 78-100, April/June.Curitiba.

FLORES, G. A. A. (2010), «La comunicación en La Resiliencia de Los Alunnos Ingresantes a La Universidad Nacional de San Agustín de Arequipa, 2009».www.ongopd.com. Peru.

FONTES, A. P. (2010), «Resiliência, segundo o paradigma do desenvolvimento ao longo da vida (life-span)». Revista Kairós, São Paulo, caderno temático 7, junho.

GEM, (2012). Empreendedorismo no Brasil. Disponível em http://www.ibpq.org.br/gem/publicações-detailphp?id=83

GOFFMAN, E. (1963), Stigma. Englewood Cliffs. NJ: Prentice Hall.

GREEFF, A. P.; JOUBERT, A. M. (2007), «Spirituality and resilience in families in which a parent has died». Psychol Rep.; Jun;100(3 Pt 1):897-900. 
GROTBERG, E. H. (1997), «La resiliencia em acción». Trabajo presentado em el Seminário Internacional sobre Aplicación del Concepto de Resiliencia em Proyectos Sociales. Universidad Nacional de Lanús, Fundación Bernard van Leer.

(2005), «Introdução: novas tendências em resiliência». In: MELILLO, A.; OJEDA, E. N. S. Resiliência: descobrindo as próprias fortalezas. Porto Alegre: Artmed.

HAMILTON, J. L.; HOFFMAN, W. S.; BROMAN, C. L.; RAUMA, D. (1993), «Unemployment, distress, and coping: A panel study of autoworkers». Journal of Personality and Social Psychology, 65(2), 234-247.

HISRICH, R. D.; PETERS, M. P.; SHEPHERD, D. A. (2009), Empreendedorismo. 7ํㅡㄹ. Editora Bookman, Porto Alegre.

INFANTE, F.(2005), «A resiliência como processo: uma revisão da literatura recente». In: MELILLO, A.; OJEDA, E. N. S. Resiliência: descobrindo as próprias fortalezas. Porto Alegre: Artmed Editora.

LAZARUS, R.; FOLKMAN, S. (1984), Stress, Appraisal and Coping. New York: Springer Publishing Company.

LUTHAR, S. S. (2000), The construct of resilience: applications in interventions. Keynote address, XX-XII Banff International Conference on Behavioral Sciences, Banff, AB, Canada.

LUTHAR, S. S.; ZIGLER, E. (1991), «Vulnerability and competence: a review of research on resilience in childhood». American Journal of Orthopsychiatry, 61, 6-22.

MASTEN, A. S. (2001), Ordinary magic: resilience processes in development. American Psychologist, 56 (3), 227-238.

McCLELLAND, D. C. (1961), The achievement society. Princeton, N.J.: Van Nostrand Co.

MELILLO, A.; OJEDA, E. N. S. (2005), Resiliência: descobrindo as próprias fortalezas. Porto Alegre: Artmed Editora.

MINELLO, I. F. (2010), «Resiliência e insucesso empresarial: um estudo exploratório sobre o comportamento resiliente e os estilos de enfrentamento do empreendedor em situações de insucesso empresarial, especificamente em casos de descontinuidade do negócio». 321f. Tese de Doutorado - Faculdade de Economia, Contabilidade e Administração, USP - São Paulo.

MINTZBERG, H. (2011), Management não é o que você pensa. Porto Alegre: Bookman.

MINUCHIN, S. (1990), Família, Funcionamento \& Tratamento. Porto Alegre: Artes Médicas, p. 25-69.

MITROFF, I. I. (2001), Crisis leadership. Executive excellence. [S.I.], v.18, n 8, p.19, aug.

OJEDA, E. N. S. (1997), «Perfil del niño resiliente. Trabajo presentado en el Seminario Internacional sobre Aplicación del Concepto de Resiliencia en Proyectos Sociales, Universidad 
Nacional de Lanús, Fundación Bernard van Leer», In: MELILLO, A.; OJEDA, E. N. S. Resiliência: descobrindo as próprias fortalezas. Porto Alegre: Artmed Editora.

ORTIGARA, A. A.; GRAPEGGIA, M.; CANDIDO, M. S. (2011), "Causas que condicionam a mortalidade e/ou sucesso das micro e pequenas empresas no estado de Santa Catarina». Revista CAP- no5 - vol.5, Ano 5.

PAYNE, R.; HARTLEY, J. (1987), "A test of a model for explaining the affective experience of unemployed men». Journal of Occupational Psychology, 60, 31-47.

RICHARDSON, R. J. (2011), Pesquisa social: métodos e técnicas. 3ª Ed. São Paulo: Atlas.

ROBINSON, S. (2007), «Business failure rates: a look at sex and location». Academy of Entrepreneurship Journal; 13, 1; Entrepreneurship pg. 45.

RUTTER, M. (1985), Resilience in the face of adversity. Protective factors and resistance to psychiatric disorder. Br J Psychiatry;147:598-611.

SAMPIERI, R. H.; COLLADO, C. F.; LUCIO, P. B. (2006), Metodologia de Pesquisa. São Paulo: McGraw-Hill Interamericana do Brasil Ltda.

SHEPHERD, D. A. (2003), «Learning from business failure: propositions of grief recovery for the selfemployed». Academy of Management Review 28(2): 318-328.

WERNER, E.; SMITH, R. (1992), Overcoming the odds: High risk children from birth to adulthood. Ithaca, NY: Cornell University Press.

WILLIAMS, S. (1987), "Goffman, interactionism, and the management of stigma in everyday life». In: SCAMBLER, G. (ed). Sociological theory and medical sociology. London: Tavistock.

YUNES, M. A. M. (2003), «Psicologia Positiva e Resiliência: o foco no indivíduo e na família». Psicologia em Estudo, Maringá, v. 8, num. esp., p. 75-84.

YUNES, M. A. M.; SZYMANSKI, H. (2001), «Resiliência: noção, conceitos afins e considerações críticas». In: TAVARES, J. (Org.). Resiliência e Educação, (pp. 13-42). São Paulo: Cortez. 